\title{
Women's experiential journey toward voluntary childlessness: an interpretative phenomenological analysis
}

\author{
Voluntary childlessness is a relatively novel yet growing phenomenon. It has implications on \\ fertility rates, our ageing society, health and social care, and economic growth. This idiographic \\ study explored three women's experiential journeys toward voluntary childlessness to help \\ understand this phenomenon and its impact on contemporary society. Semi-structured interviews \\ were carried out and analyzed using Interpretative Phenomenological Analysis. Themes identified \\ were: the legacy of feminism, models of mothering, and owning the choice to be childless. Despite \\ defining 'voluntary childlessness' as an unequivocal decision, the women's experiential accounts \\ revealed an intrinsic complexity in their journeys toward childlessness. Factors including beliefs \\ in equality, independence and career aspirations competed with constructs of \\ mothering/motherhood, partnership and choice to create a complex tapestry of contributory \\ factors in these women's childlessness. The findings question the notion of choice and particularly \\ women's ownership of that choice. The journeys toward childlessness that these women shared \\ reveal a synthesis of agentic decision-making, personal histories and challenging lifestyle choices \\ bound up within an existential need to be a woman. Further research is needed to fully understand \\ the role of voluntary childlessness within society’s notion of family, its care systems, and its \\ impact on future generations.
}

Keywords: Voluntary childlessness; female identity; family; interpretative phenomenological analysis.

This study investigated meanings attributed to ‘voluntary childlessness’. An idiographic approach was taken using Interpretative Phenomenological Analysis (IPA; Smith, Flowers \& Larkin, 2009) to analyze three British women’s experiential journeys toward identifying themselves as voluntarily childless.

Recent changes in UK fertility patterns show that birth rates fell to 1.63 children per woman on average in 2001 (below the population replacement level of 2.1; ONS, 2005a) and This is the submitted version of the now published article: Shaw, R.L. (2011). Women's experiential journey toward voluntary childlessness. Journal of Community \& Applied Social Psychology, 21(2), 151-163. 
although there was a slight increase to 1.96 in 2008 (ONS, 2008a), the largest growth is among women aged 40 and above. This may be due to more women having their first child later (Rollins, 1996) or more people deciding to opt out of parenthood altogether (Hakim, 2003). Furthermore, increasing numbers of migrant women at childbearing age have contributed to the recent increase (ONS, 2008a).

The success of medical science has meant improved mortality which, when coupled with a decline in fertility rates, could be problematic for future generations. For the first time in recorded history, the percentage of people living in UK under 16 has dropped below those at state pensionable age (ONS, 2008b). This impacts on already over-stretched health and social care services. Ill health increases with age as does the likelihood of consulting health and social care services; the largest proportion (43\%) of money spent on personal social care in 2007 was on services for older people (ONS, 2008c). One way society has dealt with this is by families providing informal care for their ageing relatives: in 2001, $78 \%$ of social care provided in the community was delivered by a family member (ONS, 2005b). The problem is clear: if the number of people choosing not to have children continues to increase society will no longer be able to rely on adults caring for their elderly parents.

This is not a manifesto for increasing fertility rates because other factors are at stake: the world is already filled with densely and over populated areas struggling to meet demands for food, health care and housing; and then we have dwindling energy supplies of gas and oil to consider and the impact children have on our 'carbon footprint'. Rather than promoting one lifestyle (with children or without) over another, what is needed is an in-depth investigation of our changing society and social networks so we can better understand the life paths available, their benefits and challenges, before moving on to determine how these impact on society. What we currently know about motivations for childlessness is limited, which is why this study was designed to explore it further. This is the submitted version of the now published article: Shaw, R.L. (2011). Women's experiential journey toward voluntary childlessness. Journal of Community \& Applied Social Psychology, 21(2), 151-163. 
Existing psychological research has focused on attempting to predict what sort of woman would choose not to have children. The following reasons for remaining childless have been identified: more reliable birth control, later marriage and marital breakdown, higher levels of education, high status employment which women are reluctant to risk, heightened concern about the environment and general state of society, partner's wishes, less time with partner, emotional strain, responsibility and lack of patience (Langdridge, Sheeran \& Connolly, 2005; Dalphonse, 1997; Kiernan, 1989). Others have used measures of masculinity and femininity, which typically cast childless women as more 'masculine’, categorizing them as 'early articulators' (women who made a decision not to have children before marriage) or 'postponers' (women who remain childless due to circumstance rather than an explicit decision; Callan, 1984; Callan \& Que Hee, 1984). Other research has approached voluntary childlessness as a social phenomenon. For example, Cannold (2004) described her Australian sample according to their 'baseline orientation to motherhood' with respect to their imagined futures and identities, as opposed to when a decision was made. Her classification included 'childless by choice' and 'childless by circumstance'; the latter was broken down again to include 'thwarted mothers' and 'waiters and watchers'.

The bulk of literature has tackled voluntary childlessness discursively from a feminist perspective; while previous generations of women would consider it 'natural' to become a mother, increasing opportunities for women in the workplace and dramatic changes in ways of living mean that motherhood is no longer a 'gender fate' (Beck \& Beck-Gernsheim, 1995). Nevertheless, Gillespie’s (2001) study of socio-historical discourses of womanhood identified powerful ideologies which convey femininity as commensurate with motherhood. One is the discourse of submission and obedience to God's will present in religious doctrine; another is the medicalization of reproductive technology which maintains patriarchal power over women's bodies and further promotes motherhood, even 'against the odds', i.e. with This is the submitted version of the now published article: Shaw, R.L. (2011). Women's experiential journey toward voluntary childlessness. Journal of Community \& Applied Social Psychology, 21(2), 151-163. 
increased use of artificial reproductive technology (ART; Snowden, 1998). Another force which unites Western-nation states in the normalization of motherhood is pro-family legislation: in the US, the Republican Right continues to preserve 'traditional family values' and restricts the availability of abortion; in the UK, Brown's Labour has strengthened its Working Families policy through measures such as family tax credit schemes and increased maternity and paternity leave (Department of Trade and Industry, 2006); and in Australia the maternity payment (or 'Baby Bonus’) has increased by 40\% since its introduction in 2004 (Carmichael \& Whittaker, 2007). These initiatives normalize the nuclear family and with it heterosexuality, monogamy and raising children. Anyone who does not fit within this narrow framework becomes marginalized:

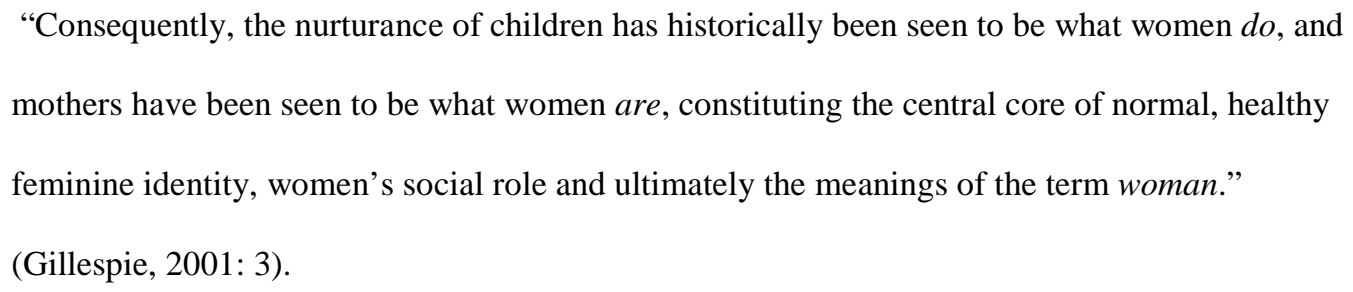

As the majority of existing research has been survey based or at the societal level, this study will examine the conceptualizations of voluntary childlessness by investigating the personal experience of choosing to remain childfree and what it means to be identified as voluntarily childless.

\section{Method}

University ethical approval was granted to solicit an opportunistic sample using invitations to UK-wide electronic mailing lists. This study was part of a larger project investigating voluntary childlessness from different perspectives. The women included here were selected on the basis that they defined themselves as voluntarily childless during data collection. All volunteers were asked to sign a consent form and informed of their right to withdraw. All

This is the submitted version of the now published article: Shaw, R.L. (2011). Women's experiential journey toward voluntary childlessness. Journal of Community \& Applied Social Psychology, 21(2), 151-163. 
data were kept confidential and participants were given pseudonyms to protect their anonymity.

\section{Participants}

The participants, Judith, Beth and Lily are all white professional women: Judith was aged 47, Beth 40 and Lily 28. Due to its focus on individuals' accounts of particular experiential phenomena, IPA research suggests recruiting a homogeneous sample as far as possible. This sample is homogeneous in terms of ethnicity and professional status.

\section{Data collection}

Participants were interviewed individually and encouraged to tell the story of their journey toward voluntary childlessness. The interview was guided by a semi-structured schedule but was flexible in order to privilege participants' voices (Mishler, 1996). Open-ended questions were asked, for example: 'how did you come to describe yourself as voluntarily childless?' Interviews were audio-recorded and transcribed verbatim.

\section{Analysis}

Interpretative phenomenological analysis (IPA; Smith, Flowers \& Larkin, 2009) was used to examine individuals' experiential accounts (e.g., Eatough \& Smith, 2006; Shaw, 2004). It takes from hermeneutics the importance of interpretation and involves a 'double hermeneutic': “The participants are trying to make sense of their world; the researcher is trying to make sense of the participants trying to make sense of their world” (Smith \& Osborn, 2008: 53). From Heideggerian phenomenology, IPA takes its interest in being-in-theworld (Heidegger, 1962). The temporality and historicity of human experience is considered paramount which drives IPA's idiographic commitment to investigating the person's experience in context (Reid, Flowers \& Larkin, 2005).

This is the submitted version of the now published article: Shaw, R.L. (2011). Women's experiential journey toward voluntary childlessness. Journal of Community \& Applied Social Psychology, 21(2), 151-163. 
The analysis proceeded on a case by case basis as described by Smith \& Osborn (2008). The first transcript was read several times to achieve generic understanding. It was then read more closely and the text separated into meaning units. For each meaning unit, a descriptive summary of the experience the participant recounted was written. Following this, interpretative coding was undertaken and salient themes identified before moving on the next case. Interpretative themes from each woman's account were then synthesized to produce the themes presented.

\section{Reflexivity}

Engaging in reflexivity is crucial when making sense of human experience (Shaw, in press). In this analysis, the process of hermeneutic reflection was considered most appropriate. This involved "continually reflecting upon our interpretations of both our experience and the phenomena being studied so as to move beyond the partiality of our previous understandings and our investment in particular research outcomes” (Finlay, 2003: 108). A reflexive journal was kept throughout.

\section{Results}

Themes identified in the analysis are: the legacy of feminism, models of mothering and owning the choice to be childless. At the start of the interview, each woman was asked for a definition of ‘voluntary childlessness' and each assumed it involved an unequivocal decision:

\footnotetext{
“a couple who have deliberately chosen not to have children [Interviewer: yeah] for whatever reason they’ve made an active decision not to have children” (Beth)
}

\footnotetext{
"Women who choose well I suppose it could be broader than just women I mean you could apply it to their partners as well but situations where people have no fertility problems or other reasons that would be an obstacle to having children but they've just made that sort of lifestyle choice that they don't want to have children" (Judith)
}

This is the submitted version of the now published article: Shaw, R.L. (2011). Women's experiential journey toward voluntary childlessness. Journal of Community \& Applied Social Psychology, 21(2), 151-163. 
"Erm I think it refers to someone who has the option to have children whether biologically or not by other means but chooses not to” (Lily)

Several assumptions are implicit here. Firstly, Beth assumed the decision is made by a (heterosexual) couple. Judith introduced motivation - a "lifestyle choice" - attributing agency to couples as did Beth’s “deliberate” choice. Judith suggested that voluntarily childless people would not have any (known) fertility problems while Lily argued that people who cannot conceive biologically may choose not to have children through other means (e.g., ART or adoption) making them voluntarily childless too. In summary, these definitions stress the voluntary aspect of this childlessness inferring that it is actively decided upon by individuals or couples.

\section{The legacy of feminism}

Using the literature as a starting point, and taking into account the ages of the women who took part, it was almost inevitable that feminism would contribute in some way to the discussion. Perhaps unsurprisingly, it played the strongest role in Judith’s account because she lived her teenage years in the sixties. Judith drew on feminist concepts of equality, independence and freedom to pursue a career as significant to her own voluntary childlessness:

\footnotetext{
"I suppose there's a strand of feminist influence in the sense of when I was young I was very aware of erm as a woman not wanting to feel pushed into a traditional role if that wasn’t what I wanted [..] it was an exciting time because I felt I was part of a generation that would erm stick two fingers up at all that and say 'no I'm going to do whatever I want to do, I'm going to have a career, I can be whatever I want to’. [..] I suppose I felt resistant to compromising a career and being independent and having the freedom, and that I saw having children as being an obstacle with all of that” (Judith)
}

This is the submitted version of the now published article: Shaw, R.L. (2011). Women's experiential journey toward voluntary childlessness. Journal of Community \& Applied Social Psychology, 21(2), 151-163. 
In this extract Judith positioned herself as rebellious, following her own path rather than one prescribed by tradition. Reflecting on her younger self, she stressed feminism as what attracted her to a life without the "obstacle” of children. Although the intervening years and the advent of a "post-feminist era”, later led Judith to see those 'ideals' as unachievable and potentially irrelevant to the everyday world:

\footnotetext{
“despite people saying it’s a post-feminist era you know men still don't do their share, they're not you know there are still different expectations about roles of men and women and there are certainly very big differences in terms of what men and women do with regard to you know domestic stuff, with or without children, and certainly with regard to childcare” (Judith)
}

Despite this gendered domestic scenario, which Judith implied was overly demanding on women, she did reminisce about the past when women were housewives and men breadwinners, but when mothering was a shared experience conducted in a communal environment:

\footnotetext{
"I think we live in such a fragmented society [..] we're living in smaller households and families don't- aren’t around to help share, because I think that's what I enjoyed as a child and what I plugged into was that collective stuff with all the cousins and everybody else's children and aunties and uncles and next door neighbours whose doors were always open [..] so I think we need to break down some of those barriers to collective living and share that sort of thing and I think that's the thing about motherhood that- that we've got an over focus on motherhood" (Judith)
}

Judith remembered a sense of community where families lived in and out of each others' houses. The received wisdom of extended families and shared nurturing they bring seemed to Judith to offer something more than the isolated way of living today. Judith felt that because of changes in ways of living the responsibility of raising children has shifted to women as

This is the submitted version of the now published article: Shaw, R.L. (2011). Women's experiential journey toward voluntary childlessness. Journal of Community \& Applied Social Psychology, 21(2), 151-163. 
individuals, instead of the community at large, who are nevertheless expected to perform their mothering role autonomously and successfully.

Related to this is the notion of motherhood as natural which Beth referred to in her rejection of it. What is remarkable in Beth's account though is not the lack of a "maternal burning desire” but Beth’s surprise at herself for feeling this way:

Beth: I do think it's a bit weird that I don't that I've never worried about not having children, I have thought a few times perhaps that's a bit weird Interviewer: but then why- why should it be weird? Beth: well I'm female, aren’t women supposed to want children. Even when I had that conversation [about whether to have children] with John [husband] you would have thought I'd be really upset or something [..] I didn’t get upset afterwards about what was said, just it seems strange

Beth’s account raised anxieties about how childlessness impacted on her external self. Our relational self is constituted by and communicated through the way we choose to live our lives and Beth seemed concerned that her rejection of motherhood brought with it a form of defeminisation. The ordinariness of motherhood is also evident in Lily's social negotiation of her self as voluntarily childless:

\footnotetext{
“it does make you feel like a bit of a freak [..] because you're the odd one out [..] you just feel like the person who doesn't fit in, the person who's life isn't as fulfilled, which is crazy, what a sad situation” (Lily)
}

Lily oriented toward feeling stigmatized. Her experience of being voluntarily childless is characterized by the way she thinks others judge her for this. There was tension between Lily's sense of others' feelings toward her and her assessment of the situation as unfair. She saw herself as a freak - or thought that others saw her as a freak - because she “doesn't fit This is the submitted version of the now published article: Shaw, R.L. (2011). Women's experiential journey toward voluntary childlessness. Journal of Community \& Applied Social Psychology, 21(2), 151-163. 
in”. At the same time, she suggested the reason others think she is a freak is because she is living an unfulfilled life; hence, according to Lily's view of society, having children is not only normal and natural but the only path to a fulfilling life. Given this assumption, it is not surprising Lily casts herself a freak. Nevertheless, Lily presented an alternative assessment of this "sad situation" as an unfair way to judge childless women when she rejected it as “crazy”. This short extract reveals the work Lily felt she needed to do to present her childfree self as a legitimate member of society. Despite having taken advantage of the increased educational and career opportunities for women in contemporary culture, thanks to the feminist movement, Lily felt that choosing a career over children will never be construed as a defensible choice for a woman:

\footnotetext{
"I think if people see you as choosing work over children then they think you're making the wrong choice because children are so much more important of course they are because they're living beings [..] that's still a much more worthy thing to do with your life than to you know get a good job.” (Lily)
}

This again highlights the negativity Lily attributed to her voluntary childlessness. She constructed it as a competition - career versus motherhood. Lily’s interpretation focused on the benefits of having children to contribute to the gene pool which lead her to a positive assessment of motherhood compared with the less important contribution of “a good job”.

The legacy of feminism is complex for these women. As someone who experienced the feminist movement firsthand, Judith initially celebrated the positive effect it had and each woman participating, as a professional, is in some way a product of feminism.

Notwithstanding the new opportunities brought about by social change, each woman questioned the legacy of feminism. While women are now able to participate equally in education, have a successful career, and be economically independent, Lily has shown us the This is the submitted version of the now published article: Shaw, R.L. (2011). Women's experiential journey toward voluntary childlessness. Journal of Community \& Applied Social Psychology, 21(2), 151-163. 
allure of motherhood as a 'natural' and fulfilling alternative may always be perceived by others as superior. Beth’s concern about her lack of maternal desire illustrates the central place of motherhood within contemporary constructions of womanhood. And Judith's nostalgia for a close-knit community demonstrates the challenge and potential loneliness of motherhood in the twenty-first century.

Despite these problems, Judith, Lily and Beth have identified themselves as voluntarily childless and the next theme will explore in some depth the personal histories that contributed to this construction of the self.

\section{Models of mothering}

It is not uncommon for children's play to involve 'faux parenting' and the construction of 'happy families' in their imagined futures. In talking about her journey toward childlessness, Lily revealed that she had always imagined that she would have children and from being a young girl, she had forged a fantastical view of motherhood:

\footnotetext{
"we'd be in like this little house erm and yeah I'd probably have two kids or maybe more but probably two and they'd have blonde hair and it'd be all cool and we'd get up in the morning and we'd be singing and I'd be putting them in the bath and stuff and then we'd go out to the park and we'd do all this nice stuff and it's kind of wonderful and yeah there'd be all kind of this idyllic little dream” (Lily)
}

Lily's construction of motherhood draws upon the stereotypical simplicity of ' 2.4 children' and living 'happily ever after'; in her own words, an “idyllic little dream”. Reading that quote conjured a dreamscape of fuzzy images with bright sunshine, a fairy-tale cottage and a lush green meadow the like of which might feature in a children's storybook. Indeed, this is an image Lily created in childhood. However, she did not leave it in the past. As Lily continued

This is the submitted version of the now published article: Shaw, R.L. (2011). Women's experiential journey toward voluntary childlessness. Journal of Community \& Applied Social Psychology, 21(2), 151-163. 
to describe this idealized view of motherhood it became clear that this is something she had contemplated more recently. In her "idyllic little dream”, Lily imagined herself as “quite a good mum":

\footnotetext{
"I think I might have been a bit crazy but probably would have been quite a good mum. I did think that being a mother would change me for the better that I'd become a less selfish person and you know it'd bring out this really good caring about other people kind of side [..] you do sort of see it in a pink tinged perfect way with your little pram and everything and it's not like that in reality” (Lily)
}

Alongside her childlike picture of happy families, Lily considered that becoming a mother would hold personal benefits in terms of creating an acceptable and 'socially approved' persona. In doing this, Lily constructed an alternative ending to explore the possibilities of life had she made different choices. This demonstrates Lily's active self-reflection; she is clearly someone who has thought through her current situation and considered alternative life paths before choosing the route which led to her self-categorization as voluntarily childless. These extracts also illustrate the salience of imagined and idealized models of mothering and their potential impact on women's journeys toward childlessness.

Instead of the somewhat romantic image Lily created, Judith took her model of mothering from her past:

\footnotetext{
“because I didn’t like the way my mother behaved with me and my sister, a really strong part of my identity forming was about not being like her [...] because she’s now got dementia I was sort of revisiting my relationship with her and trying to make sense of it and through talking that through in counselling I became aware that erm I spent a lot of my formative years trying to not be my mother and part of that came out as not wanting to be $a$ mother” (Judith)
}

This is the submitted version of the now published article: Shaw, R.L. (2011). Women's experiential journey toward voluntary childlessness. Journal of Community \& Applied Social Psychology, 21(2), 151-163. 
Judith shared her experience of counselling and among the topics of discussion was her mother's recent illness which encouraged Judith to explore her maternal relationship in some depth. The extract above constituted the result of a great deal of reflective work and represented Judith's current thinking about her own life choices in the context of her experience of being mothered. Having done this work, Judith was faced with the realization that her wish to avoid modelling her own mother's behaviour did in some way contribute to her childlessness. Judith's sister though took the opposite path which illustrates that the same circumstances do not always lead to a similar outcome:

\footnotetext{
“her response was that's not how to do it, I know how to do it and I'm going to do it in my way and I'm going to be completely different with my children, whereas I just shied off it completely” (Judith)
}

Beth’s thinking about her childfree status was in some ways more organic than the rehearsed positions of Lily and Judith. It became clear that Beth had not reflected at length on her life choice to remain childfree and that some of the things she discussed emerged in-themoment as she explored her own experiential journey. In doing this, Beth began to speak about her mother:

\footnotetext{
"I’ve got a very difficult relationship with my mother. She’s got a mental illness as well as a physical illness [..] she’s erm demanding, she’s like a spoilt child actually she demands an awful lot of attention [..] it's certainly true that the difficulty I've had with my mother etcetera certainly has influenced whether or not we'd have had children in our case, definitely. [..] She probably is one of the reasons why I haven’t got children.” (Beth)
}

Beth's candid description of her maternal relationship revealed an almost tangible sense of absence that had been overwhelmed by duty; absence of the loving and supportive mother

This is the submitted version of the now published article: Shaw, R.L. (2011). Women's experiential journey toward voluntary childlessness. Journal of Community \& Applied Social Psychology, 21(2), 151-163. 
model set against the duty of care Beth felt toward her mother resulting in the somewhat ironic situation of Beth mothering her own mother ("she’s like a spoilt child actually").

This theme has illustrated the prominence of models of mothering both in terms of these women's own lived experience of being mothered and its potential impact on the decision to remain childless and in terms of the idealized visions of motherhood which function to perpetuate the myth of the 'happily ever after'. The final theme will further uncover the nuances of the phenomenon of voluntary childlessness by using these women's accounts to deconstruct the notion of choice.

\section{Owning the choice to be childless}

At the beginning we saw each woman prioritize choice by defining voluntary childlessness as an unequivocal decision. However this theme will question the nature of that choice by exploring issues of agency and circumstance that contributed to these women's journeys toward voluntary childlessness. The first example sees Beth construct her childlessness as something borne out of circumstance rather than a definite decision:

\footnotetext{
“it just sort of happened really we didn’t get- I’m now forty, we didn’t get married until I was thirty-five, although I was with John for ten years before that although I wasn’t living with him, so we'd had a fifteen year relationship erm I always imagined I'd probably have children [..] but never really sort of got round to it” (Beth)
}

This was Beth's opening gambit regarding her childlessness; it came early on in the interview and worked to contextualize her current relationship status, her age, and her childlessness. In this extract there was little to reveal Beth's feelings about remaining childfree as she has presented it in a very matter of fact way. Later on in the interview Beth talked through the decision-making process she underwent with her partner:

This is the submitted version of the now published article: Shaw, R.L. (2011). Women's experiential journey toward voluntary childlessness. Journal of Community \& Applied Social Psychology, 21(2), 151-163. 
“about sort of a year in [to the marriage] we sort of said you know time’s getting on, I’m now thirty-six, you know, one needs to just make the decision one way or another and though I think we'd actually both make really really lovely parents erm John said he didn’t really want to share me with anybody and after what we'd been through [with Beth's mother] so he thought it was quite late for us to start having children erm and I wasn't that bothered either way to be perfectly honest I just accepted his decision and I don't think [Beth knocks on the table] the tape can't hear me touching wood erm we're perfectly happy with that decision. It doesn't bother us at all. I've got no particular desire to have children. I might regret it when I'm seventy I might not” (Beth)

In this extract we learned a great deal more about the factors that contributed to Beth's childlessness, some of which might make us question whether it falls within the remit of what is voluntary. Firstly, Beth described needing to make a decision with her partner about whether to have children soon after they were married. This is set within the context of her age and is tinged by a sense of lost time; Beth inferred that her "difficult relationship" with her mother impacted negatively on her relationship and delayed her marriage, which prevented her from addressing this earlier. Beth’s summary of her discussion with her husband positioned him as pro-actively endorsing childlessness in order to fully commit to their marriage. In turn, Beth presented herself as reactive yet content with this proposal. Despite this, Beth still felt the need to position herself and John as potentially "really really lovely parents”. By doing this, Beth pre-empted and quashed the potential accusation that childless individuals take that path because they would fail as parents. She also pointed to her possible future regret which demonstrates a pragmatic stance toward life choices. It also conceptualized voluntary childlessness as contingent on time; a past experience, a current reflection, a future regret each existing along the continuum illustrating the significance of time in understanding this phenomenon.

This is the submitted version of the now published article: Shaw, R.L. (2011). Women's experiential journey toward voluntary childlessness. Journal of Community \& Applied Social Psychology, 21(2), 151-163. 
Judith’s story also involved some intricate negotiations between circumstance and choice. In her thirties Judith was sterilised and at the time, as well in the years building up to her sterilisation, she identified her feminist beliefs as central to this decision:

\footnotetext{
“if you'd asked me this question in my twenties I'd have talked about all the sort of feminist things and wanting to be independent and have a career [... in my thirties I was so adamant that I wasn't going to have children that I've been sterilised so I can't have children and I have no doubts that that was what I thought at the time. And I think on balance it is right” (Judith)
}

With the benefit of work carried out in counselling Judith analyzed her life choice to be sterilised from an experiential distance. In this extract Judith hinted at self-deception or perhaps denial; in her twenties and thirties, the dominant feeling driving her desire to remain childfree was a belief in equality and independence for women and the chance to escape the 'gender fate’ of motherhood. Now in her forties Judith contemplated whether less conscious feelings contributed which had only come to light more recently:

\footnotetext{
"I know when I worked out all the feelings I'd had when I was younger I felt sort of cheated of having the choice taken away, which is stupid because I mean I did it in my thinking erm nobody deliberately did it to me, but, I don't say so much cheated but I felt a sense of loss that that door wasn’t open anymore, erm but with a bit of space, I was, you know, I did go through a sort of sense of grief for that at the time but with a bit of distance from that now erm I think actually I may well not have had children anyway” (Judith)
}

Through engaging in a process of directed self-reflection, Judith begun to deconstruct what she had previously seen as an unequivocal decision to be sterilised. She described the process of reflection as "painful” particularly because she now believed it related so strongly to her relationship with her mother. The sense of time is especially salient in Judith’s account

This is the submitted version of the now published article: Shaw, R.L. (2011). Women's experiential journey toward voluntary childlessness. Journal of Community \& Applied Social Psychology, 21(2), 151-163. 
because it switches between a retrospective self-analysis and an evaluation of her current state of mind:

“having said all of that, if you'd asked me the question and I answered honestly, I'm not without regret. But I'm not deeply troubled by regret and the regrets aren’t a burden” (Judith)

It is the wisdom of hindsight which seemed to enable Judith to rationalize her childlessness and to openly explore the way she felt about it now.

Lily's case is rather different but no less complicated: after they were married, Lily’s husband discovered he had severe fertility problems which meant a natural conception was deemed impossible and reproductive treatment was unlikely to be successful. For some, this prognosis would exclude Lily from identifying as voluntarily childless but Lily defined herself as such because she chose not to take up alternative (non-biological) methods of having children:

\footnotetext{
“I found this out erm about a year after we'd been married and that was like obviously really devastating. And they did think for a while that there might be other routes that we could go down, so we looked into those and over the like past four, five years we've found that actually no, the other sort of medical routes aren't going to be viable either. Erm so that leaves you with adoption and we've talked it over and talked it over and just decided we just don't want to go down that route so I guess, even though biologically it's not an option that's available to me, it is a voluntary choice erm not to adopt and actually that makes me feel a bit more in control of the whole situation because then it's not that poor me I can't have them it's like okay my options are limited but at the same time there's still options and I'm choosing not to take those ones and to go in a different direction.” (Lily)
}

Lily described her self-endorsed identity of a voluntarily childless woman as a mechanism for managing her childlessness. Previously, we saw the work Lily felt was necessary to position This is the submitted version of the now published article: Shaw, R.L. (2011). Women's experiential journey toward voluntary childlessness. Journal of Community \& Applied Social Psychology, 21(2), 151-163. 
her sense of self as legitimate within a world she believed constructs motherhood as the only fulfilling fate for a woman. From this extract we learn that this work is crucial in building Lily's sense of internal control. Moreover, it is essential for her to feel authentic. As the interview moved on, Lily appeared reconciled with her decision to remain childfree, that is, the decision she made with her husband not to adopt. However, at times she returned to the difficulty of the medical ‘truth’ which challenges her self-construction as voluntarily childless:

\footnotetext{
“So it's a really mixed thing but I think I've forced myself to think of the positives [of not having children] to try and cope with it. So I don't think it's like a 'oh yeah I'm so empowered this is wonderful I feel great about this decision'. I think part of me is still annoyed that it’s partly been taken out of my hands but I'm trying to be positive and feel empowered that I've made a choice not to adopt because we could do that.” (Lily)
}

This illustrates the lived experience of situated freedom; we can make life choices only within the constraints of the social world in which we live. For Lily, evoking a sense of control enabled her to rationalize her childlessness and to learn to live a life that is different from what she had anticipated in her dreamlike vision. Again, this emphasizes the significance of our personal relationships and time, as something we live through and which contextualizes our sense of self, in the journey toward childlessness.

Each woman seemed to deconstruct the notion of choice and, arguably, none of them fully owned their choice to be childfree: Beth constructed it as largely her husband's decision and a result of her mother's illness; Judith attributed it to feminist ideals and the inappropriate mothering model she experienced; and Lily’s decision to remain childfree was triggered by the realization that she would not be able to have a biological child with her husband. These

This is the submitted version of the now published article: Shaw, R.L. (2011). Women's experiential journey toward voluntary childlessness. Journal of Community \& Applied Social Psychology, 21(2), 151-163. 
complex interactions between circumstance and choice underline the challenge of understanding the potentially contested and dynamic phenomenon of voluntary childlessness.

\section{Discussion}

This study has examined three women's experience of voluntary childlessness. Each woman defined herself as voluntarily childless and when asked to describe that status in general terms saw it as something borne of an unequivocal decision. Their lived experience of voluntary childlessness was rather more complex though. The legacy of feminism illustrates the varied impact feminism had on these women's constructions of voluntary childlessness. Judith's sterilisation was driven by a desire to avoid the 'gender fate' (Beck \& BeckGernsheim, 1995) of motherhood and instead capitalize on opportunities brought about by feminism. However, this impact was not experienced as wholly positive by these women. Judith's impression that domestic practices do not exhibit the same equality that has been achieved in the workplace is corroborated by previous research. Artis \& Pavalko (2003) found that despite growing numbers of households with dual earners and the common practice of pooling income to support a chosen lifestyle, women are still more likely to do the majority of housekeeping tasks, including being the primary carer of any children.

Furthermore, the voluntary childless men and women in Park’s (2005) study perceived parenthood as a sacrifice: women thought it an obstacle to career aspirations, as did Judith; men saw it as a financial sacrifice. It is not surprising that women, like those who took part in this research, would seek a successful career and financial independence and see motherhood as an obstacle to those things. What we learn from Lily's account though is that professional women may not feel assimilated into society until they have also fulfilled their 'calling' to become a mother. So instead of feminism offering women a choice between children and career, it has left them feeling pressurized to have both (Shaw \& Giles, 2009).

This is the submitted version of the now published article: Shaw, R.L. (2011). Women's experiential journey toward voluntary childlessness. Journal of Community \& Applied Social Psychology, 21(2), 151-163. 
The impact of this dual life goal for women is intensified when we consider Beth and Lily's experience of feeling de-feminized and stigmatized as voluntarily childless women. Previous literature supports these experiential claims. Women without children have been defined by what is missing; they are 'barren’, childless, non-mothers (Letherby, 1994). Moreover, Hird \& Abshoff (2000) argued that the ‘childless woman’ has been socially constructed as an oxymoron: "Indeed, in most societies to choose to remain childless is perceived as somehow 'unnatural', so deeply inscribed and culturally scripted are essentialist ideas of womanhood” (Miller, 2005: 58). Beth’s concern was that somehow she did not match up to her expectations of what it meant to be a woman because she did not experience a 'maternal desire' for children. This position evoked the well rehearsed discourse of motherhood as natural and its reverse, the 'unnaturalness' of non-motherhood. Certainly, existing evidence has demonstrated that women who are not mothers are 'called to account for themselves' in ways that mothers are not (Morell, 1994). In other words, women who choose not to have children are ‘othered' because they do not follow the agreed script.

Furthermore, the language used in this field is contentious. Voluntary childlessness is said to have derogatory connotations: childlessness denotes a lack, hence supporting the discursive strategies which marginalize women without children; instead, using the term childfree implies freedom of choice (Veevers, 1980). This sense of marginalization and the stigma experienced by Lily is supported by the extant literature. Park (2002) found that negative stereotyping meant that some voluntarily childless individuals felt the need to alter or justify their position and did so by adopting a range of mechanisms. Some rejected the pronatalist discourse by 'condemning the condemners' or proactively redefining voluntary childlessness as a valid social role, while others claimed biological deficiency, passed over or substituted their identity in order to preserve a 'good' self.

This is the submitted version of the now published article: Shaw, R.L. (2011). Women's experiential journey toward voluntary childlessness. Journal of Community \& Applied Social Psychology, 21(2), 151-163. 
More recent findings from Australia however turn this stigma on its head: Carmichael \& Whittaker (2007) found that negative attributions of childless women as selfish, for example, tended to come from the childless women themselves rather than parents or others planning to have children. Indeed, Maher \& Dever (2004) found that mothers respected other women's choices not to have children which suggests a sea-change in public perceptions of voluntary childlessness; any negativity experienced by women who choose not to have children may be self-constructed and internalized rather than it being something directed at them by others. This is a possible explanation for Lily’s experience of stigmatization; although she felt like a "freak", we do not know from this analysis whether Lily’s social network or others in society would confirm the negative self-image she had constructed. Nevertheless, Lily's experience of stigmatization was real and therefore contributes to her lived experience as a voluntarily childless woman. A recent Media Framing Analysis of UK news media coverage relating to voluntary childlessness found a range of positive and negative ways in which messages were framed. Some rehearsed the childless-as-other discourse that was present in earlier work (e.g. Park, 2005, 2002; Gillespie 2001) but others indicated a shift toward more positive representations of childfree women in popular culture (Giles, Shaw \& Morgan, 2009). Of course, this may be due in part to the increasing number of journalists who are childfree women (e.g. Defago, 2005). Notwithstanding these moves toward a greater acceptance of childfree women and away from the dominant prejudice one might have expected not long ago, this recent evidence indicates that approaching voluntary childlessness from an experiential perspective is crucial to understand its impact on the everyday lives of individuals.

The models of mothering theme revealed the significance of Beth and Judith's relationships with their own mothers in forging their futures as childless women. The stories they shared are in some way supported by Reading \& Amatea's (1986) finding that choosing This is the submitted version of the now published article: Shaw, R.L. (2011). Women's experiential journey toward voluntary childlessness. Journal of Community \& Applied Social Psychology, 21(2), 151-163. 
not to have children may be the result of childhood trauma, poor parenting roles or some other negative experience of childrearing. Judith's description of her sister's reaction to their experience of being mothered however demonstrated that similar circumstances do not always lead to similar outcomes; and during her interview Beth expressed concern about bringing a child into the world that may be susceptible to mental health problems since she and her sister, as well her mother, had experienced them. Nevertheless, this is an issue which has been under-researched and which this analysis has confirmed requires further exploration. It is not surprising that one's own experience of being mothered would play some part in determining whether motherhood will be a chosen life course. These data have demonstrated that this relationship is not straightforward however and that other factors such as aspirations for independence, career or health issues may also be influential. What is surprising is that previous research has focused largely on the meanings of motherhood compared to nonmotherhood without addressing subjective experiences of being mothered or mothering outside of the nuclear family structure. During her interview, Judith described caring for her nieces and nephew and Beth described her experience of mothering her own mother. These findings therefore suggest the need to breakdown constructions of 'the family' in contemporary culture as well as understanding the structure of personal relationships and their impact on life choices we make.

The final theme, owning the choice to be childless, indicates the need to unpack the term 'voluntary childlessness' and furthermore to understand the place of childlessness within the lives of men and women in contemporary Western culture. Previous research has increasingly criticized the old-fashioned categorizations of 'early articulators' and 'postponers' (Callan, 1984; Callan \& Que Hee, 1984). The findings of this study also question the more recent labels of 'childless by choice' and 'childless by circumstance', which is further divided into 'thwarted mothers' and 'watchers and waiters', introduced by This is the submitted version of the now published article: Shaw, R.L. (2011). Women's experiential journey toward voluntary childlessness. Journal of Community \& Applied Social Psychology, 21(2), 151-163. 
Cannold (2004). In one respect, Lily may occupy the position of 'thwarted mother' because, as she said, to some degree at least her choice was taken away from her. But in order to manage this circumstance, she pro-actively occupied the position of 'childfree by choice'. Similarly, Beth could be construed as a 'waiter and watcher' because she described her childlessness as something that “just happened”. However, she was not waiting until an opportunity to become a mother arose; she was already in a long-term relationship but other factors, including her mother and her marriage, had taken priority. Judith presents a dilemma because according to the reflective account given in the interview, she had at one time considered herself ‘childfree by choice' but then later in life began to wonder whether she too had had an element of choice taken away. Nevertheless, in her conclusion that "on balance" she had made the right choice, Judith demonstrates that she does, to some degree, own that choice.

This sense of ownership is something one must negotiate within the short- and longerterm projects of life. As we have seen in these women's accounts, an unequivocal decision is something that reflects autonomy, empowerment and a sense of assuredness about the future a decision will bring. Life is far from simple; paths cross unexpectedly, relationships breakdown, careers move in unanticipated directions, illness disrupts familial networks, all of which may overturn rational decisions made previously prompting change. Given the significance of time in understanding the nature of human experience (Heidegger, 1962), it becomes meaningless to construe voluntary childlessness as something that is static and enduring. The experiential accounts analyzed demonstrate the inherent complexities in women's journeys toward childlessness and the multifaceted factors that contribute to paths taken. In short, these findings suggest that further research is needed to unravel the complex and interacting components of personal and social factors which have contributed to the

This is the submitted version of the now published article: Shaw, R.L. (2011). Women's experiential journey toward voluntary childlessness. Journal of Community \& Applied Social Psychology, 21(2), 151-163. 
increasing numbers of men and women deciding not to have children. Each of the accounts analyzed here mirrors the conclusion of Carmichael \& Whittaker (2007):

"While 'choice' is unprecedented, the [... evidence is that family formation is intimately negotiated, rationalized and experienced through dynamic interplay between material conditions, personal aspirations, gender relations, social values and biological limitations.”

The depth of meaning examined in this study demonstrates the benefits of taking an idiographic approach to such a complex phenomenon. Nevertheless, it does raise questions regarding potential future research particularly with groups not investigated here. Although some studies reviewed have included men, there is clearly a need to understand their position more fully. We do not know whether men contemplate fatherhood as something which is socially expected. Nor do we know whether masculinity is experienced as contingent upon reproduction or 'good' fathering. The sample in this study spanned the twenties, thirties and forties but it would be beneficial to learn whether women in their teens or early twenties and post-menopausal women feel differently about voluntary childlessness. Given the diversity of contemporary European communities, further work with men and women with different religious beliefs and from different ethnic backgrounds is also required to explore whether religiosity or cultural tradition play a role in men and women's journeys toward childlessness. In addition, recent legal developments in civil partnership and gay adoption may impact on the life pathways available to these individuals making voluntary childlessness something worthy of investigation in this population.

Further phenomenological work is certainly needed for us to develop our understanding of voluntary childlessness as lived. It is clear that changing times have prompted a need for ‘ontological security’ (Giddens, 1991) among women; moving away from taken-for-granted gender role stereotypes brings with it the need to re-negotiate a fulfilling life path for women who choose to remain childfree. Indeed, future research needs This is the submitted version of the now published article: Shaw, R.L. (2011). Women's experiential journey toward voluntary childlessness. Journal of Community \& Applied Social Psychology, 21(2), 151-163. 
to be sensitive and reflective in order to take into account the ways in which we are “continuously revising our own individual biographies as part of the reflexive project of the self” (Miller, 1005; 47). Taking a phenomenological approach to meaning-making, as inspired by Bruner (1990), will help to unravel the complexities uncovered in future studies.

Although this study has identified the sometimes blurred distinction between voluntary and involuntary childlessness, it would be helpful for national statistics to document reasons cited for childlessness. This would radically enhance what we know about the context of current fertility rates. This would also help contextualize what we already recognize as an ageing society. Beth's case illustrated that providing informal care for family members may indeed impact on whether that younger generation has children of its own. Furthermore, as the Adult Social Care Workforce itself ages, the focus has to be on how it will cope with growing capacity, how it will establish new skills and attract and train new workers to care for increasing numbers of elderly people (Department of Health, 2008).

In conclusion, the findings presented have demonstrated the fluidity of the phenomenon of voluntary childlessness. It was experienced differently by these women but similarities in their life journeys have shown that voluntary childlessness emerges from a complex mix of agentic decision-making, personal histories and challenging lifestyle choices bound up within an existential need to be a woman.

\section{References}

Artis, J.E. \& Pavalko, E.K. (2003). Explaining the decline in women’s household labor: individual change and cohort differences. Journal of Marriage and Family, 65, 746-761. Beck, U. \& Beck-Gernsheim, E. (1995). The normal chaos of love. Cambridge: Polity Press. Bruner, J. (1990). Acts of meaning. Cambridge, MA: Harvard University Press.

This is the submitted version of the now published article: Shaw, R.L. (2011). Women's experiential journey toward voluntary childlessness. Journal of Community \& Applied Social Psychology, 21(2), 151-163. 
Callan, V.J. (1984). Voluntary childlessness: early articulator and postponing couples. Journal of Biosocial Science, 16(4), 501-509.

Callan, V.J. \& Que Hee, R.W. (1984). The choice of sterilisation: voluntary childless couples, mothers of one child by choice, and males seeking reversal of vasectomy. Journal of Biosocial Science, 16(2), 241-248.

Cannold, L. (2004). Declining marriage rates and gender inequity in social institutions: towards an adequately complex explanation for childlessness. People and Place, 12(4), 1-11. Carmichael, G.A. \& Whittaker, A., (2007). Choice and circumstance: qualitative insights into contemporary childlessness in Australia. European Journal of Population, 23, 111-143.

Dalphonse, S. (1997). Choosing to be childfree. ZPG Report, 29(3), 106.

Department of Health (2008). Putting people first - working to make it happen. Adult Social Care Workforce Strategy - Interim statement. Produced by COI for Department of Health. Available at: www.dh.gov.uk/en/Publicationsandstatistics/Publications/PublicationsPolicyAndGuidance.D

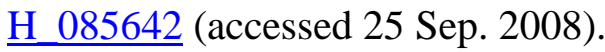

Department of Trade and Industry (2006). Work and Families Act 2006. Available at: http://www.dti.gov.uk/employment/employment-legislation/workandfamiliesact/index.html (accessed 22 Aug. 08).

Eatough, V. \& Smith, J.A. (2006). 'I feel like a scrambled egg in my head': an idiographic case study of meaning making and anger using interpretative phenomenological analysis. Psychology and Psychotherapy, 79: 115-135.

Finlay, L. (2003). Through the looking glass: intersubjectivity and hermeneutic reflection. In L. Finlay \& B. Gough (Eds.) Reflexivity: a practical guide for researchers in health and social sciences. Oxford: Blackwell Publishing.

Giddens, A. (1991). Modernity and self-identity. Cambridge: Polity Press.

This is the submitted version of the now published article: Shaw, R.L. (2011). Women's experiential journey toward voluntary childlessness. Journal of Community \& Applied Social Psychology, 21(2), 151-163. 
Giles, D.C., Shaw, R.L. \& Morgan, W. (2009). Representations of voluntary childlessness in the UK press, 1990-2008. Journal of Health Psychology, 14, 1218-1228.

Gillespie, R. (2000). When no means no: disbelief, disregard and deviance as discourses of voluntary childlessness. Women’s Studies International Forum, 23(3), 223-234.

Hakim, C. (2003). Childlessness in Europe: summary of research results for the Economic and Social Research Council project funded by research grant RES-000-23-0074, Dec 02-Jul 03.

Heidegger, M. (1962). Being and time. Oxford: Blackwell.

Hird, M.J. \& Abshoff, K. (2000). Women without children: a contradiction in terms? Journal of Comparative Family Studies, 31(3), 347-355.

Langdridge, D., Sheeran, P. \& Connolly, K. (2005). Understanding the reasons for parenthood. Journal of Reproductive and Infant Psychology, 23(2), 1210133.

Letherby, G. (1994). Mother or Not, Mother or What? Problems of definition and identity. Women’s Studies International Forum, 17(5), 525-232.

Maher, J. \& Dever, M. (2004). What matters to women: beyond reproductive stereotypes. People and Place, 12(3), 10-17.

Miller, T.A. (2005). Making sense of motherhood: a narrative approach. Cambridge: Cambridge University Press.

Mishler, E.G. (1986). Research interviewing: context and narrative. Cambridge, MA: Harvard University Press.

Morrell, C.M. (1994). Unwomanly conduct: the challenges of intentional childlessness. London: Routledge.

ONS (2005a). Fertility: continued rise in 2005. Available at: www.statistics.gov.uk/CCI/nugget.asp?ID=951 (accessed 22 Aug. 2008).

This is the submitted version of the now published article: Shaw, R.L. (2011). Women's experiential journey toward voluntary childlessness. Journal of Community \& Applied Social Psychology, 21(2), 151-163. 
ONS (2005b). Health and social care: 2.8m aged 50+ provide unpaid care. Available at: www.statistics.gov.uk/CCI/nuggetasp?ID=1268 (accessed 25 Sept 2008).

ONS (2008a). Live births: fertility highest for 34 years. Available at: www.statistics.gov.uk/cci/nugget.asp?id=369 (accessed 25 Sep. 2008).

ONS (2008b). Ageing: more pensioners than under-16s for first time ever. Available at: www.statistics.gov.uk/CCI/nugget.asp?ID=949 (accessed 25 Sep. 2008).

ONS (2008c). Personal social services: over £20bm spent in England in 2006/07. Available at: www.statistics.gov.uk/CCI/nugget.asp?ID=1959 (accessed 25 Sep. 2008)

Park, K. (2002). Stigma management among the voluntarily childless. Sociological Perspectives, 45(1), 21-45.

Park, K. (2005). Choosing childlessness: Weber's technology of action and motives of the voluntarily childless. Sociological Inquiry, 75(3), 372-402.

Reading, J. \& Amatea, E.S. (1986). Role deviance or role diversification: reassessing the psychological factors affecting the parenthood choice or career-oriented women. Journal of Marriage and the Family, 48, 255-260.

Reid, K., Flowers, P. \& Larkin, M. (2005). Exploring lived experience. The Psychologist, 18, 20-23.

Rollins, J.H. (1996). Women's minds, women's bodies: the psychology of women in a biosocial context. Upper Saddle River: Prentice-Hall, Inc.

Smith, J.A. \& Osborn, M. (2008). Interpretative phenomenological analysis. In J.A. Smith (Ed.) Qualitative psychology: a practical guide $\left(2^{\text {nd }}\right.$ Ed.). London: Sage.

Smith, J.A., Flowers, P. \& Larkin, M. (2009). Interpretative phenomenological analysis: theory, method and research. London: Sage.

Shaw, R.L. (2004). Making sense of violence: a study of narrative meaning. Qualitative Research in Psychology, 1, 131-151.

This is the submitted version of the now published article: Shaw, R.L. (2011). Women's experiential journey toward voluntary childlessness. Journal of Community \& Applied Social Psychology, 21(2), 151-163. 
Shaw, R.L. (in press). Embedding reflexivity within experiential qualitative psychology. Qualitative Research in Psychology.

Snowden, R. (1998). Psychological discontinuities introduced by the new reproductive technologies. Journal of Community \& Applied Social Psychology, 4(8), 249-259.

Veevers, J. E. (1980). Childless by choice. Toronto: Butterworth \& Co. (Canada) Ltd.

This is the submitted version of the now published article: Shaw, R.L. (2011). Women's experiential journey toward voluntary childlessness. Journal of Community \& Applied Social Psychology, 21(2), 151-163. 